\title{
INJÚRIA POTENCIAL DE HERBICIDAS DE SOLO AO GIRASSOL. I - Clomazone ${ }^{1}$
}

\author{
RIBAS A. VIDAL ${ }^{2}$ e NILSON G. FLECKS ${ }^{3}$
}

\begin{abstract}
RESUMO
Conduziu-se um ensaio de campo na Estação Experimental Agronômica da Universidade Federal do Rio Grande do Sul, em Eldorado do Sul, RS, em 1989/90. 0 objetivo deste trabalho foi determinar o efeito residual potencial do herbicida clomazone, aplicado em três doses à superfície do solo (PRE) ou incorporado no mesmo (PPI), sobre a cultura de girassol. Através de ensaio complementar, realizado em casa-devegetação em 1990, procurou-se determinar o local de absorção de clomazone por plântulas de girassol. A localização de clomazone no solo foi muito importante na determinação de sua injúria para o girassol. A campo, clomazone

promoveu injúria mais acentuada nas plântulas, quando aplicado em PRE do que em PPI. Clomazone, aparentemente, foi mais absorvido pelo hipocótilo do que pelo sistema radicular das plântulas de girassol. No entanto, nas maiores doses, a fitotoxicidade em PPI se acentuou com o decorrer do tempo, a ponto de desaparecerem as diferenças entre épocas de aplicação.

Palavras-chave: Helianthus annuus, herbicidas residuais, dissipação de herbicidas, persistência no solo, rotação de culturas, local de absorção.
\end{abstract}

\section{ABSTRACT \\ Potential sunflower injury by soil applied herbicides. I-Clomazone}

A field experiment was carried out during 1989/90 at the Eldorado do Sul Experimental Station of Federal University of "Rio Grande do Sul", Brazil, with the objective of evaluating potential injury to sunflower by clomazone applied at three different dosages in pre-emergence (PRE) or preplant incorporated (PPI). A greenhouse trial was carried out in 1990 to determine the site of uptake for clomazone from the soil.

Clomazone placement in the soil was very important in determining the level of injury to the plants. The level of injury to seedlings was higher when clomazone was sprayed in PRE as compared to PPI. Apparently, more clomazone was absorbed through the sunflower hypocotyl than by the root system. Late season assessments indicated that higher dosages were equally phytotoxic under both application methods.

Additional index words: Helianthus annuиs, residual herbicide, dissipation of herbicides, soil persistence, tillage, crop rotation, site of absorption.

\section{INTRODUÇÃO}

A época recomendada para a semeadura de girassol no Rio Grande do Sul é o final do inverno e início da pri- mavera (agosto/setembro) (Silva, 1988 e Silva \& Mundstock, 1988). Essa recomendação, aliada ao fato de que o girassol possui ciclo curto (100-140 dias), permite a intensificação do uso da terra através da técnica de sucessão/rotação

\footnotetext{
1 Recebido para publicação em 06/04/93 e na forma revisada em 10/12/93. Extraído da dissertação apresentada pelo primeiro autor para obtenção do grau de mestre em Fitotecnia pela Faculdade de Agronomia da Universidade Federal do Rio Grande do Su1 (UFRS), Porto Alegre, RS. Trabalho parcialmente financiado pelo CNPq (Processo $\mathrm{n}^{\circ}$ 41402489-3/AG).

2 Eng. Agr., M.Sc., Prof. Auxiliar, Departamento de Plantas de Lavoura da UFRS/Faculdade de Agronomia, Av. Bento Gonçalves, 7712, Caixa Postal 776, CEP 90001-970, Porto Alegre, RS.

3 Eng $^{\circ}$.- Agr ${ }^{\circ}$., Ph. D., Prof. Adjunto, Departamento de Plantas de Lavoura da UFRS/Faculdade de Agronomia. Bolsista do CNPq.
} 
de culturas (Robinson, 1966; Robinson, 1978 e Silva, 1988). Contudo, o intervalo entre a semeadura da soja, milho ou feijão num ano e a semeadura do girassol no ano seguinte é curto, podendo ocorrer persistência de compostos herbicidas empregados na primeira cultura. E conhecido, por exemplo, o fato de atrazina aplicada na cultura do milho comprometer o desenvolvimento do girassol no ano seguinte, levando as plantas a apresentar sinais evidentes de alteração das clorofilas, necrose e secamento dos tecidos e morte das plantas (Vranceanu, 1977 e Wilkins \& Swallers, 1982).

A persistência de um herbicida no solo deve-se, dentre outros, à influência dos seguintes fatores: decomposição química, adsorção aos colóides do solo, lixiviação, volatilização, fotodecomposição, absorção e decomposição pelas plantas e/ou microorganismos.

Clomazone, uma isoxazolidinona, apresenta forte adsorção aos colóides do solo, o que lhe confere alta persistência. Sua meia-vida no solo varia entre 28 e 84 dias, dependendo das condições ambientais (WSSA, 1989). Dessa forma, doses elevadas podem afetar a cultura do trigo que se segue a da soja (WSSA, 1989). Entre as culturas mais sensíveis à clomazone encontra-se o girassol (Halstead \& Harvey, 1988). Quando ocorrerem altas temperaturas e chuvas abundantes durante o ciclo da soja, a degradação do produto será mais acentuada (Gallandt et al., 1989). Curran \& Knake (1987) relataram que plântulas de milho cultivadas um ano após a aplicação de clomazone apresentaram 39\% de injúria, sendo observada a morte de algumas delas.

O aparecimento de sintomas do herbicida depende não só da quantidade presente no solo, mas também do seu posicionamento no solo e do local de absorção do herbicida pelas plantas. Blackman \& Deveson (1990), por exemplo, comprovaram a importância da absorção de herbicidas pelo hipocótilo e epicótilo para o controle de espécies dicotiledôneas, enquanto outros autores demonstraram o efeito da absorção pelo coleóptilo para o controle de gramíneas (Knake \& Wax, 1968 e Knake et al., 1967).

O objetivo deste trabalho foi avaliar o efeito residual potencial do herbicida clomazone à cultura do girassol e determinar o local de absorção de clomazone pelas plântulas de girassol.

\section{MATERIAL E MÉTODOS.}

\section{A) Efeito residual potencial.}

Um experimento foi conduzido em campo durante a estação de crescimento 1989/90, na Estação Experimental Agronômica (EEA) da Universidade Federal do Rio Grande do Sul (UFRS), localizada no município de Eldorado do Sul, RS, região fisiográfica da Depressão Central do Estado.

O solo onde foi realizado o experimento é classificado como Podzólico Vermelho-Escuro álico (PAULEDULT). A análise química do solo revelou teor de matéria orgânica de 2,1\%; pH em água de 5,4; fósforo disponível $20 \mathrm{ppm} \mathrm{e}$ potássio trocável $140 \mathrm{ppm}$. A CTC efetiva foi 3,96 e o teor de argila $35 \%$.

O preparo do solo constou de uma aração com arado de disco e duas gradagens. A aração foi realizada no dia 17 de julho de 1989 e a primeira gradagem foi realizada três dias após. A outra gradagem foi efetuada após a adubação.

A adubação do solo, realizada cinco dias antes da semeadura, foi distribuída uniformemente na área, incorporada no terreno através de uma gradagem e constituiu-se de $20 \mathrm{~kg} / \mathrm{ha}$ de nitrogênio, $80 \mathrm{~kg} / \mathrm{ha}$ de P205 e $80 \mathrm{~kg} / \mathrm{ha}$ de K20, utilizando-se $400 \mathrm{~kg} / \mathrm{ha}$ da formulação 5-20-20, sendo ainda adicionado $1 \mathrm{~kg} / \mathrm{ha}$ de boro (10 kg/ha de Bórax).

$\mathrm{O}$ delineamento experimental utilizado foi o de blocos casualizados, arranjados em parcelas subdivididas, com quatro repetições. Cada bloco foi composto de duas parcelas, às quais foram destinadas as épocas de aplicação dos herbicidas (pré-plantio incorporado e pré-emergência). Cada parcela foi dividida em 12 unidades experimentais (subparcelas), nas quais foram aplicados, de forma aleatória, os tratamentos herbicidas. A área total da parcela foi de $120 \mathrm{~m}^{2}$ (4 x 30m); a da subparcela foi de $10 \mathrm{~m}^{2}(2,5 \times 4 \mathrm{~m})$, com uma área útil central de 4,5 $\mathrm{m}^{2}(1,5 \times 3 \mathrm{~m})$. A cada bloco acrescentou-se urna área extra de $10 \mathrm{~m}^{2}(2,5 \mathrm{x} 4 \mathrm{~m})$ destinada à testemunha não tratada com herbicida de solo. Cada repetição apresentou, portanto, 25 unidades experimentais (subparcelas).

Em cada época de aplicação (parcela) os tratamentos foram organizados num esquema fatorial hierárquico, isto é, foram utilizados quatro herbicidas (clomazone, chlorimuron, imazaquin e imazethapyr), cada um deles aplicado em três doses, que corresponderam àquelas usuais, meio e um décimo daquelas recomendadas pela pesquisa para utilização em soja. Esse delineamento experimental permite que se apresente aqui apenas os resultados do herbicida clomazone (Gamit), o qual foi aplicado nas doses 1000, 500 e $100 \mathrm{~g} / \mathrm{ha}$.

As aplicações dos herbicidas e semeadura do girassol foram realizadas no dia 29/8/89. Nessa ocasião, foi utilizada enxada rotativa em toda área experimental, sendo que num dos dois tratamentos (parcelas) os herbicidas foram aplicados e incorporados ao solo com aquele equipamento. No outro, os herbicidas foram aplicados após a utilização da enxada rotativa e semeadura, ficando, portanto, na superfície do solo. Esses tratamentos correspondem às épocas de aplicação e doravante serão denominados PPI (pré-plantio incorporado). e PRE (pré-emergência), respectivamente.

Os herbicidas foram aplicados com auxílio de um aparelho aspersor costal de precisão, propelido a gás carbônico, munido de quatro bicos tipo leque da série 110.04, distanciados de $50 \mathrm{~cm}$ entre si, a uma pressão constante de 175 $\mathrm{kPa}$, o que proporcionou uni volume de calda de 2501/ha.

A aplicação em PPI foi executada no horário compreendido entre as 10:40 e 12:00 horas. A aplicação em PRE foi realizada entre 14:00 e 15:00 horas. Ambas ocasiões apresentavam insolação plena e ventos com velocidade média de $6 \mathrm{~km} / \mathrm{h}$. O solo apresentava umidade de $12,6 \%$, enquanto o ar apresentava umidade relativa de 97 e $47 \%$ às $9 \mathrm{~h} 00$ e 15h00, respectivamente. Nesse dia, a temperatura máxima do ar foi de $23,4^{\circ} \mathrm{C}$ e a mínima foi de $4,2^{\circ} \mathrm{C}$.

O híbrido de girassol DK 180 foi semeado numa profundidade aproximada de $5 \mathrm{~cm}$, utilizando-se equipamento manual (saraquá), sendo adotado um espaçamento de $0,5 \mathrm{~m}$ entre linhas e $0,5 \mathrm{~m}$ entre plantas, colocando-se aproximadamente cinco sementes por cova. A emergência da cultura ocorreu 10 dias após a semeadura (8/9/89). Treze dias depois da emergência do girassol (DDE) realizou-se o desbaste das plantas, deixando-se uma planta por cova, permanecendo na área uma população de 40 mil plantas/ha, em média. 
$\mathrm{Na}$ fase inicial do ciclo da cultura (aos 5 e $24 \mathrm{DDE})$, foi utilizado o inseticida clorpirifós, na dose de $720 \mathrm{~g} / \mathrm{ha}$ (Lorsban, 1,5 1/ha), para controle preventivo de insetos de solo. Para o controle de plantas daninhas gramíneas no ensaio, realizou -se a aspersão de $480 \mathrm{~g} / \mathrm{ha}$ de haloxyfop metil (Verdict, 2,0 I/ha) em área total, aos 40 DDE.

Quando as plantas de girassol nas parcelas testemunhas apresentavam oito folhas (estádio Va), isto aos $35 \mathrm{DDE}$, foi feita uma aplicação de $80 \mathrm{~kg} / \mathrm{ha}$ de nitrogênio, na forma de uréia, distribuídos manualmente ao longo das linhas, e sem incorporação ao solo.

Durante os 40 dias após a aplicação dos tratamentos herbicidas (DAT) ocorreram precipitações pluviais freqüentes e temperaturas máximas e mínimas de $29 \pm 5^{\circ} \mathrm{C}$ e $15 \pm 5^{\circ} \mathrm{C}$.

De cada subparcela foram coletadas, com o auxílio de uma pá, seis plântulas de girassol com raízes, aos 21 DDE. As plântulas foram lavadas no momento da coleta para se fazer a separação entre o sistema radicular e o solo. Essas plântulas foram usadas para determinar-se: matéria seca da parte aérea e do sistema radicular, estatura das plântulas, comprimento da raiz principal e área foliar. Para avaliar a área foliar foi utilizado aparelho eletrônico que integrava a área foliar através de uma câmera ótica de varredura. Para avaliar a matéria seca, tanto da parte aérea como do sistema radicular, o material vegetal foi submetido à secagem em estufa com circulação de ar à $60^{\circ} \mathrm{C}$, por um período de 96 horas, e posteriormente foi pesado em balança analítica com precisão de centésimo de gramo.

Aos 51 DDE (11 dias após a aplicação do produto graminicida, mas antes que seus sintomas fossem visualizados), realizou-se avaliação visual da infestação de plantas daninhas, utilizando-se escala percentual onde 100 correspondeu ao controle completo das infestantes e zero correspondeu à ausência de controle das ervas (Frans et al., 1986). As gramíneas presentes no ensaio por ocasião da avaliação foram Digitaria ciliaris (Retz.) Koel. e Echinochloa crusgalli (L) Beauv., encontrando-se, em média, 201 e 7 plantas $/ \mathrm{m}^{2}$ na testemunha, respectivamente. As dicotiledôneas encontradas por ocasião da avaliação foram Richardia brasiliensis Gomez, Lepidium virginicum L. e Stellaria media (LI) Cyrill, constatando-se, em média, 82, 50 e 5 plantas $/ \mathrm{m}^{2}$ na testemunha, respectivamente.

Aos 100 DDE, quando as plantas se encontravam no estádio Rs, determinou-se a estatura média do girassol, avaliando-se 10 plantas por unidade experimental.

As variáveis avaliadas no experimento foram submetidas à análise de variância de acordo com o modelo de parcelas subdivididas. Quando constatada a significância de dose para o herbicida clomazone ou da interação época/dose de clomazone, procedeu-se ao desdobramento dos graus de liberdade correspondentes, utilizando-se a análise de regressão, testando-se a significância da regressão linear e desvios da mesma. Os coeficientes polinomiais ortogonais foram calculados através do método para níveis não-equidistantes, desenvolvido por Nogueira (1979). Determinaram-se as equações lineares significativas e, caso o quadrado médio dos desvios de uma regressão tenha sido significativo, utilizou-se o procedimento apresentado por Gomez \& Gomez (1984).
Cada dose herbicida foi comparada à testemunha (sem aplicação) através do teste DMS, ao nível de $5 \%$ de probabilidade. Optou-se pela utilização do teste DMS, neste experimento, principalmente para comparar a testemunha com a menor dose testada, uma vez que a análise de regressão já é suficiente para a comparação entre as doses (Chew, 1976 e Petersen, 1977).

\section{B) Local de absorção.}

Um bioensaio foi conduzido em casa-de-vegetação, entre setembro e novembro de 1990. O experimento foi repetido duas vezes. A metodologia experimental foi adaptada de Knake \& Wax (1968).

Utilizaram-se amostras de solo não tratado, retiradas do local do experimento de campo com auxílio de uma pá, até a profundidade de $10 \mathrm{~cm}$. Após a coleta o solo foi levado para laboratório, peneirado em peneira com malha de $3 \mathrm{~mm}$ e utilizado para preencher vasos plásticos, com $12 \mathrm{~cm}$ de altura e capacidade de $1000 \mathrm{~cm} 3$.

Foram estabelecidos seis tratamentos com o herbicida clomazone, o qual foi aspergido em solo numa dose correspondente a $1000 \mathrm{~g} / \mathrm{ha}$. $\mathrm{O}$ solo aspergido foi misturado para uniformizar a aplic ação herbicida e, posteriormente, para cada tratamento, foi colocado na camada compreendida entre 0-1, 1-3, 3-5, 5-7, 0-5 e 0-12 cm de profundidade dos vasos. A esses tratamentos adicionou-se uma testemunha com solo não tratado. Utilizaram-se quatro repetições por tratamento. Esses tratamentos foram aplicados com o equipamento anteriormente descrito, tomando-se o cuidado de tratar um volume uniforme de solo $\left(250 \mathrm{~cm}^{3}\right)$ nos quatro primeiros tratamentos. O quinto e sexto tratamentos foram aspergidos em 500 e $1000 \mathrm{~cm}^{3}$ de solo, respectivamente.

Foram semeadas 20 sementes por vaso do híbrido de girassol Braskalb DK 180, na profundidade de $5 \mathrm{~cm}$. Procedeu-se ao desbaste do excesso de plantas aos 9 dias após a emergência (DAE), mantendo-se seis plântulas por vaso até o $18^{\circ} \mathrm{DAE}$.

As temperaturas médias diurna e noturna na casa-devegetação foram $33 \pm 3^{\circ} \mathrm{C}$ e $21 \pm 3^{\circ} \mathrm{C}$, respectivamente. $\mathrm{Na}$ época da aplicação do herbicida o solo apresentava-se com $20 \%$ de umidade (equivalendo a $60 \%$ da capacidade de campo). Durante o decorrer do ensaio foi procedida a casualização dos vasos a cada 5 dias, para minimizar a variabilidade das condições ocorrentes na casa-devegetação.

As determinações realizadas foram: avaliação visual de clorose das plântulas aos 5 DAE, matéria seca da parte aérea c estatura das plântulas aos 9 e 18 DAB.

Os resultados foram submetidos à análise de variância. Quando o efeito dos tratamentos foi significativo, realizou-se a comparação das médias através do teste de Duncan ao nível de $5 \%$ de probabilidade.

\section{RESULTADOS E DISCUSSÃO}

\section{A) Efeito residual potencial.}

Nas avaliações quantitativas realizadas em estádio de desenvolvimento bem jovem (Figuras 1, 2 e 3), verificou-se que o herbicida clomazone promoveu efeitos menos injuriosos à parte aérea de girassol quando aplicado em PPI do que 
em PRE. Esse resultado pode ser explicado por uma ou mais das quatro hipóteses seguintes: diluição do herbicida ao solo, absorção dos vapores do herbicida, adsorção mais acentuada quando aplicado em PPI e absorção através do hipocótilo.

A diluição do herbicida no perfil do solo quando o mesmo foi incorporado pode ser constatada pelo cálculo da concentração de clomazone, que na maior dose foi de 1,5 e 5 ppm, em PPI e PRE, respectivamente. Isto equivale a 36.1014 e $125.10^{14}$ moléculas $/ \mathrm{cm}^{3}$ de solo, em PPI e PRE, respectivamente. Desta forma, a quantidade de moléculas por volume de solo foi menor quando o herbicida foi aplicado em PPI, havendo, por conseguinte, condições de ocorrer menor fitotoxicidade nessa situação. Evidências de que a diluição do herbicida no solo, devido à profundidade de incorporação, reduz o efeito fitotóxico foram mostradas por Ashton \& Dunster (1961), com o herbicida EPTC; Knake et al. (1967), com trifluralin; e Burnside (1972), com trifluralin e nitralin.

Na superfície do solo, o herbicida estaria mais exposto às condições atmosféricas e haveria maior possibilidade de ocorrer volatilização e, na forma de vapor, ser absorvido pelas plântulas de girassol. De fato, a pressão de vapor de clomazone é $1,44 \cdot 10^{-4} \mathrm{~mm} \mathrm{Hg}\left(\mathrm{a} 25^{\circ} \mathrm{C}\right.$ ), sendo um produto relativamente volátil (Keifer, 1989 e WSSA, 1989). Essa volatilização é acentuada tanto em condições onde o solo apresentava umidade $20 \%$ acima da capacidade de campo, como naquel es com umidade $20 \%$ abaixo (Halstead \& Harvey, 1988). Temperaturas ao redor de $29^{\circ} \mathrm{C}$ favoreceram a volatilização de dinoseb e o vapor era absorvido pelas plântulas, resultando em injúria mais acentuada (Davis, 1956 e Dowler et al., 1958). De fato, durante os primeiros 40 dias após a aplicação dos herbicidas ao solo houve várias ocasiões em que ocorreram temperaturas máximas do ar ao redor de $29^{\circ} \mathrm{C}$, o que reforça esta hipótese.

A adsorção de clomazone aos colóides, em PPI, implica que menor quantidade de moléculas tenha ficado na solução do solo, diminuindo a possibilidade de ser absorvidas pelo girassol. Embora a solubilidade de clomazone seja elevada (1100 mg/I), a adsorção do mesmo aos colóides do solo é acentuada (WSSA, 1989). A atividade de clomazone é inversamente proporcional à adsorção do mesmo aos colóides, ou seja, é inversamente proporcional aos teores de matéria orgânica e de argila (Loux \& Slife, 1989 e Loux et al., 1989). Portanto, conforme foi discutido anteriormente, se o herbicida for incorporado, maior será sua diluição, resultando em maior adsorção e, conseqüentemente, menor ação herbicida. $\mathrm{O}$ solo onde foi conduzido este experimento apresentava teores médios de argila e matéria orgânica, o que favoreceria a adsorção de clomazone.

Evidência de maior absorção de clomazone pelo hipocótilo do que pelo sistema radicular do girassol foi obtida no trabalho de casa-de-vegetação que se segue.

A redução do comprimento da raiz principal e da matéria seca do sistema radicular com o incremento da dose de clomazone (Figura 2) pode ser atribuída a um efeito indireto decorrente do modo de ação de clomazone, conforme descrito a seguir. As plântulas, ao terem inibida a síntese de clorofila e carotenóides (Gallandt et al., 1989 e Keifer, 1989), tiveram menor capacidade de captar energia luminosa. Nessa condição, a planta passa por um processo de adaptação, canalizando a maior parte dos fotossintatos produzidos para promover a expansão da área foliar em detrimento do crescimento do sistema radicular (Patterson, 1979 e Patterson, 1982).

Aquelas modificações promovidas pelo herbicida nas plântulas de girassol se acentuaram e ainda puderam ser observadas na avaliação da estatura realizada aos 110 DAT (Figura 3). Isso deve ter ocorrido porque, à medida que as plantas crescem, novos tecidos são formados, enquanto outros se desenvolvem, e outros, ainda, senescem. Assim, cada orgão da planta é o resultado do desenvolvimento passado

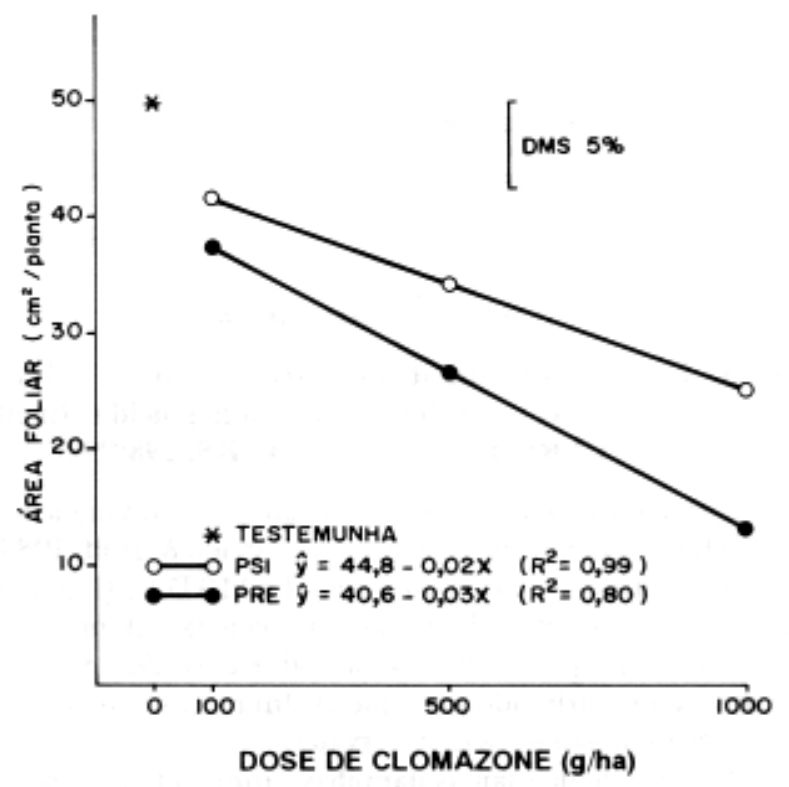

FIG. 1. Matéria seca da parte aérea e área foliar das plantas de girassol, aos 31 dias após aspersão ao solo do herbicida clomazone em duas épocas e testemunha sem herbicidas. EEA/UFRS, Eldorado do Sul, RS, $1989 / 90$.

Planta Daninha, v. 11, n. 1/2, 1993. 

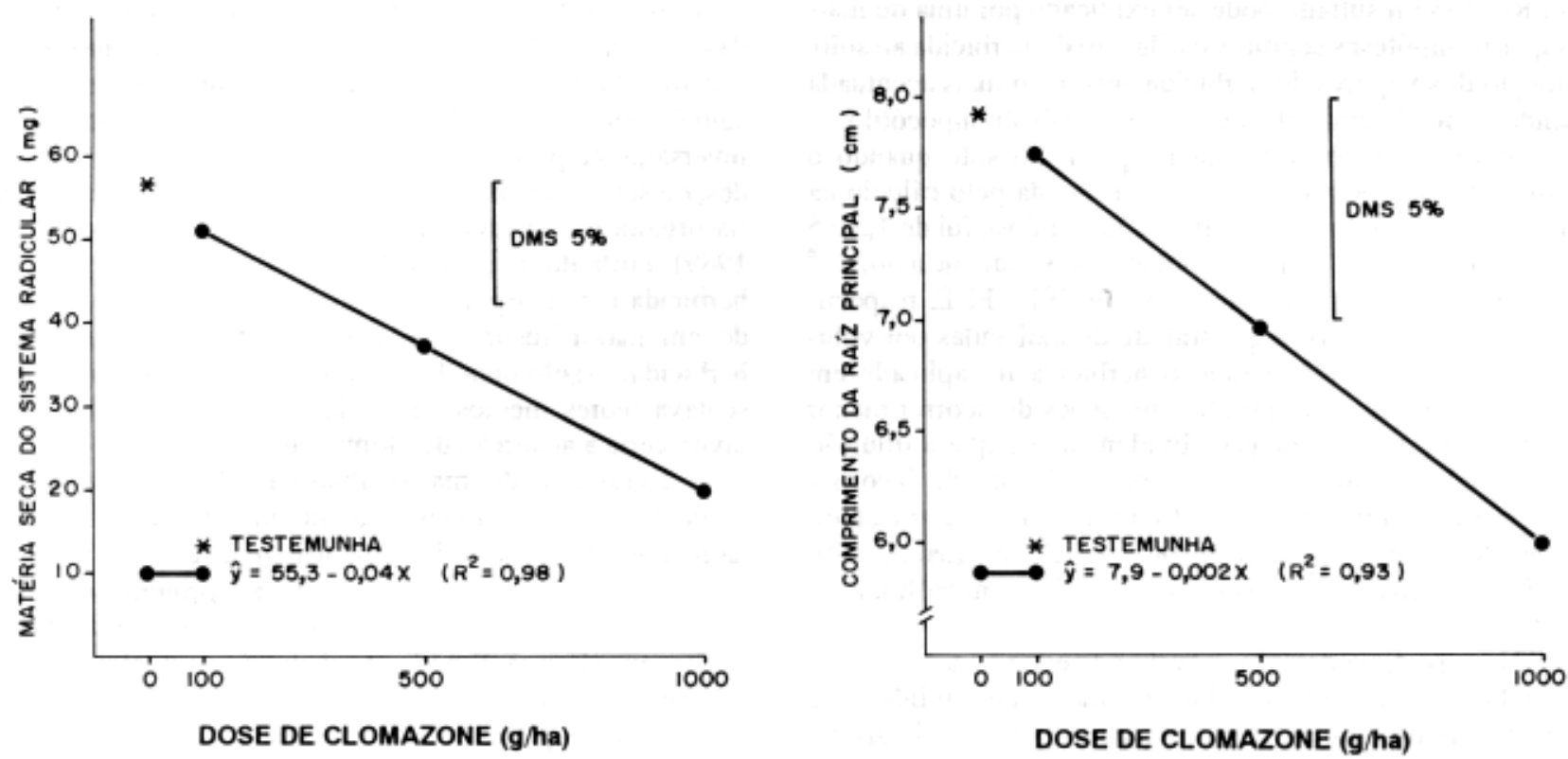

FIG. 2. Matéria seca do sistema radicular e comprimento da raiz principal das plantas de girassol, aos 31 dias após aspersão ao solo do herbicida clomazone (média de duas épocas de aplicação) e testemunha sem herbicidas. EEA/UFRS, Eldorado do Sul, RS, 1989/90.
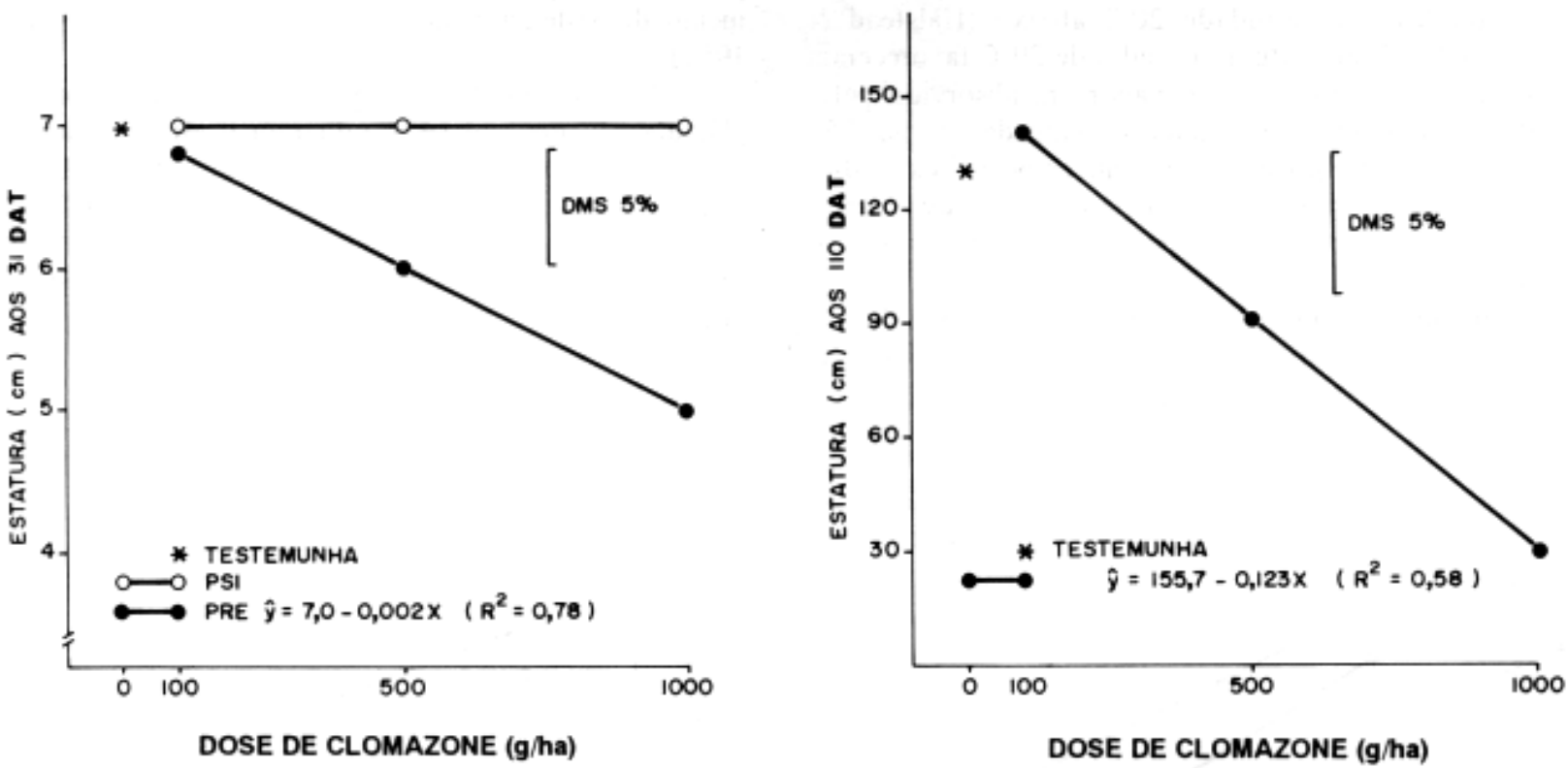

FIG. 3. Estatura das plantas de girassol, aos 31 e 110 dias após aspersão (DAT) ao solo do herbicida clomazone em duas épocas e testemunha sem herbicidas (média de duas épocas de aplicaçáo para a avaliação aos 110 DAT). EEA/UFRS, Eldorado do Sul, RS, 1989/90.

que ocorreu durante as fases iniciais do desenvolvimento da planta (Hamid \& Grafius, 1978 e Radosevich \& Holt, 1984).

A comparação da estatura aos 31 e 110 DAT (Figura 3) indica que os efeitos deletérios se acentuaram mais nos tratamentos em que se utilizou a maior dose do herbicida. Isto deve ter contribuído para que as diferenças entre épocas de aplicação já não fossem observadas.

O controle de plantas daninhas promovido pelo herbicida serve como indicativo da disponibilidade dos mesmos na camada superficial do solo, região de onde germina a maior parte das sementes destas espécies (Anderson, 1977). Neste experimento, o fato de clomazone, aplicado em PPI, ter promovido controle inadequado tanto de gramíneas como de dicotiledôneas (Figura 4) foi mais um indicativo de que, nessa situação, a diluição em maior volume de solo e a adsorção aos colóides deixaram poucas moléculas disponíveis para absorção pelas invasoras. Já a obtenção de controle mais acentuado de plantas daninhas quando aplicado em PRE, foi indicativo de que as menores diluição e adsorção deixaram disponíveis maior quantidade de moléculas para 

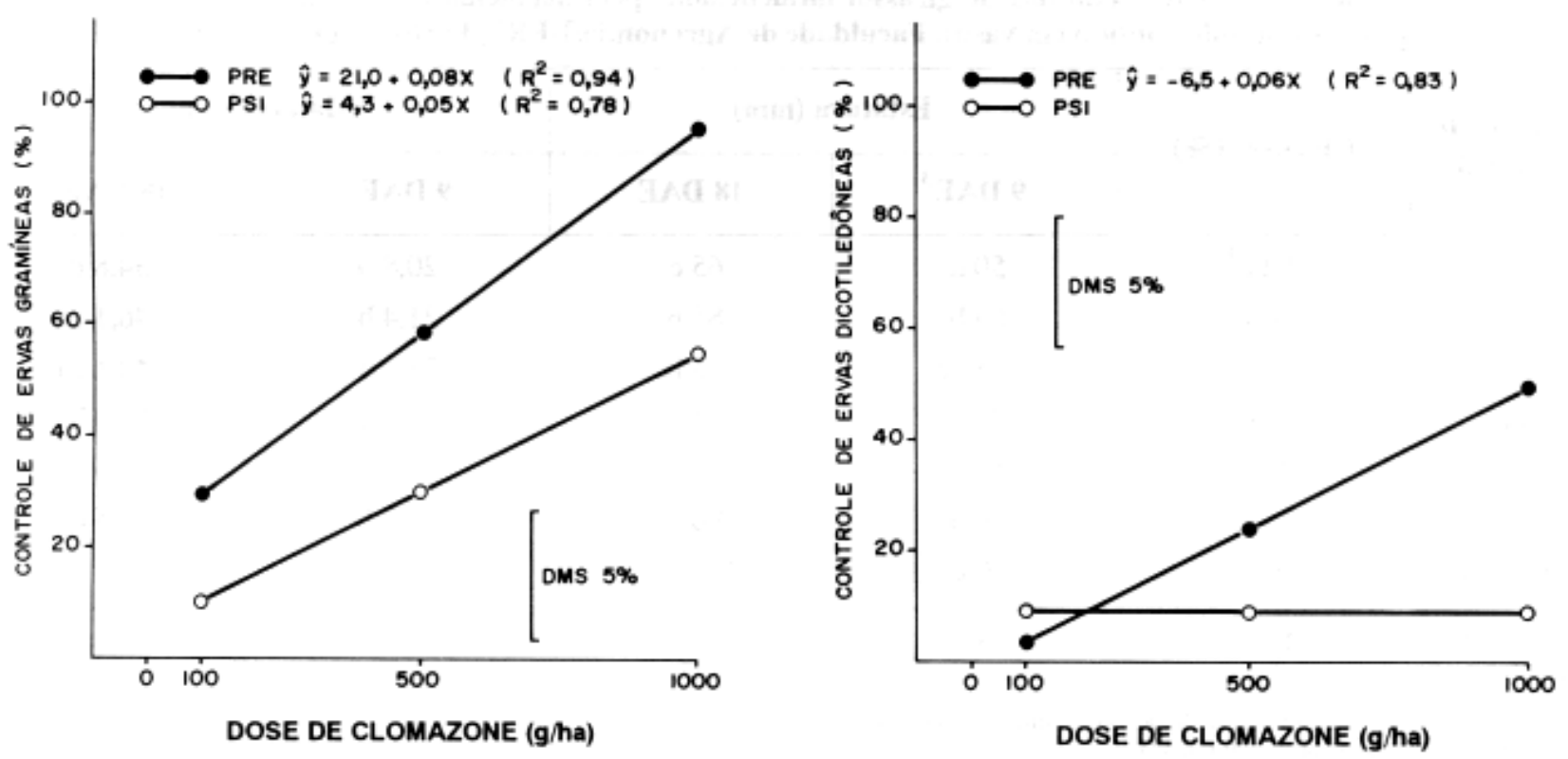

FIG. 4. Controle de ervas gramíneas e dicotiledôneas, aos 51 dias após aspersảo ao solo do herbicida clomazone em duas épocas e testemunha sem herbicidas. EEA/UFRS, Eldorado do Sul, RS, 1989/90.

absorção. O aumento da dose do herbicida promoveu um incremento no controle de plantas daninhas (Figura 4).

Utilizando-se as equações de regressão entre matéria seca da parte aérea e dose do herbicida (Figura 1), estimaram-se que as doses de clomazone necessárias na época da semeadura de girassol, para que ocorresse $50 \%$ de redução da matéria seca da parte aérea, seriam 530 e 840 g/ha, em PRE e em PPI, respectivamente.

A cinética da degradação de clomazone no solo se ajusta à equação (1) (Witt, 1989):

$$
\operatorname{Ln}([\mathrm{Cf}] /[\mathrm{Ci}])=-\mathrm{kt}
$$

onde [Ci] e [Cf] são as concentrações do herbicida indicadas no tempo inicial e final, respectivamente; $\mathrm{k}$ é a constante de degradação; e t é o tempo. A meia-vida ( $\mathrm{t} 1 / 2$, a qual ocorre quando $\mathrm{Cf}=\mathrm{Ci} / 2$ ) do herbicida no solo é calculada pela equação (2):

$$
\mathrm{t} 1 / 2=0,693 / \mathrm{k}
$$

Utilizando-se as equações 1 e 2 e admitindo-se um intervalo de 210 dias entre a aplicação dos herbicidas e a semeadura do girassol, estimou-se que a meia-vida dos herbicidas, para que promovessem $50 \%$ de redução na matéria seca (ou seja $\mathrm{Cf}=530$ e $840 \mathrm{~g} / \mathrm{ha}$ ), seria de 229 e 835 dias, para clomazone em PRE e clomazone em PPI, respectivamente. Isto significa que, se houvesse condições ambientais para que a meia-vida deste produto fosse daquela magnitude, clomazone causaria sintomas de injúria, decorrente da sua ação fitotóxica sobre a cultura do girassol. Contudo, referências de WSSA (1989) e o trabalho de Gallandt et al. (1989), que utilizaram aveia como planta reagente, indicaram que a meia-vida de clomazone varia entre 28 a 84 dias, para solos arenosos e argilosos, respectivamente. Outro trabalho (Witt, 1989), onde se estudou através do método cromatográfico o comportamento de clomazone num solo arenoso e sob semeadura direta, indicou meia-vida de apenas 10 dias.

\section{B) Local de absorção.}

Os resultados obtidos até os 9 DAE no experimento de casa-de-vegetação evidenciaram que o herbicida clomazone deve ter sido absorvido pelo hipocótilo do girassol (Tabela 1 e Figura 5). Quando o produto foi posicionado acima das sementes (0-1, 1-3 e 3-5 cm de profundidade) as plântulas emergiram apresentando clorose. Quando clomazone foi colocado abaixo das sementes $(5-7 \mathrm{~cm})$, os sintomas cloróticos só começaram a surgir aos $9 \mathrm{DAE}$; no entanto, nesta oportunidade, ainda não haviam sido observados redução de estatura e de matéria seca do girassol (Tabela 1). Embora não hajam outras publicações quanto ao local de absorção de clomazone por girassol ou outras espécies, trabalhos realizados por Blackman \& Deveson (1990) comprovaram a importância da absorção de herbicidas pelo hipocótilo e epicótilo para o controle de espécies dicotiledôneas. Da mesma forma, Knake \& Wax (1968) e Knake et al. (1967) demonstraram o efeito da absorção pelo coleóptilo para o controle de gramíneas.

$\mathrm{Na}$ Tabela 1 também pode-se constatar o efeito da profundidade de incorporação (diluição) do herbicida. Naqueles tratamentos em que clomazone esteve localizado entre $0-1,0-5$ e $0-12 \mathrm{~cm}$ de profundidade, pode-se constatar que, à medida que aumentava a profundidade de incorporação do herbicida, menores eram os efeitos nas plantas, principalmente nas avaliações realizadas aos 18 DAE.

Os resultados obtidos no ensaio de campo podem ser parcialmente explicados pelos resultados acima. Isto é, clomazone, quando aplicado em PRE, deve ter permanecido na camada superficial do solo. Com a presença de maior número de moléculas nessa camada provavelmente aumentou o número de moléculas na solução do solo, ficando assim 
R.A. Vidal \& N.G. Fleck

TABELA 1 - Características de plântulas de girassol influenciadas pelo herbicida clomazone colocado em diversas posiçōes no solo contido em vasos. Faculdade de Agronomia/UFRS, Porto Alegre, RS, 1990.

\begin{tabular}{l|c|c|c|c|c}
\hline \multirow{2}{*}{$\begin{array}{c}\text { Posiçäo do } \\
\text { herbicida }\end{array}$} & \multirow{2}{*}{ Clorose $^{\mathbf{1}}$ (\%) } & \multicolumn{2}{|c|}{ Estatura (mm) } & \multicolumn{2}{c}{ Matéria seca $^{2}$} \\
\cline { 3 - 6 } & & 9 DAE & 18 DAE & 9 DAE & 18 DAE \\
\hline $0-1 \mathrm{~cm}$ & $52 \mathrm{c}^{\mathbf{3}}$ & $50 \mathrm{~d}$ & $65 \mathrm{c}$ & $20,8 \mathrm{~b}$ & $34,8 \mathrm{~d}$ \\
$1-3 \mathrm{~cm}$ & $66 \mathrm{~b}$ & $69 \mathrm{~b}$ & $85 \mathrm{~b}$ & $21,4 \mathrm{~b}$ & $46,1 \mathrm{c}$ \\
$3-5 \mathrm{~cm}$ & $75 \mathrm{a}$ & $65 \mathrm{bc}$ & $75 \mathrm{bc}$ & $21,9 \mathrm{~b}$ & $40,1 \mathrm{~cd}$ \\
$5-7 \mathrm{~cm}$ & $0 \mathrm{c}$ & $102 \mathrm{a}$ & $121 \mathrm{a}$ & $28,2 \mathrm{a}$ & $60,0 \mathrm{~b}$ \\
$0-5 \mathrm{~cm}$ & $81 \mathrm{a}$ & $57 \mathrm{~cd}$ & $75 \mathrm{bc}$ & $20,2 \mathrm{~b}$ & $39,5 \mathrm{~cd}$ \\
$0-12 \mathrm{~cm}$ & $28 \mathrm{~d}$ & $69 \mathrm{~b}$ & $90 \mathrm{~b}$ & $21,7 \mathrm{~b}$ & $44,5 \mathrm{c}$ \\
testemunha & $0 \mathrm{e}$ & $100 \mathrm{a}$ & $126 \mathrm{a}$ & $28,5 \mathrm{a}$ & $75,5 \mathrm{a}$ \\
\hline C.V. ${ }^{5}(\%)$ & 13,1 & 8,4 & 12,0 & 9,1 & 9,9 \\
\hline
\end{tabular}

1 Avaliaçāo visual em escala de 0 (verde) a 100 (totalmente amarela).

2 Matéria seca da parte aérea, em mg/planta.

$3 \mathrm{DAE}=$ Dias após a emergếncia.

4 Médias, comparadas na vertical, seguidas pela mesma letra nāo diferem significativamente pelo teste de Duncan ( $\mathrm{P}=0,05)$.

5 C.V. = Coeficiente de variaçăo.

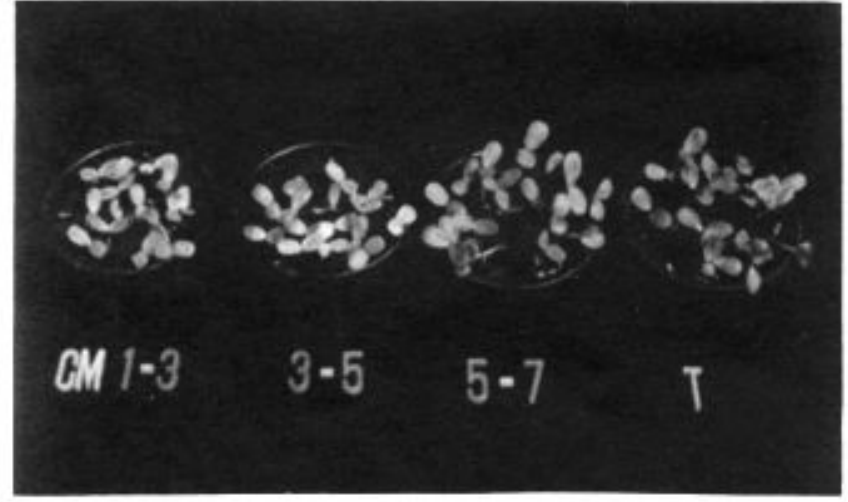

FIG. 5. Clomazone colocado acima $(1-3$ e $3-5 \mathrm{~cm})$ e abaixo $(5-7 \mathrm{~cm})$ das sementes de girassol, comparados à testemunha sem herbicida, aos $\mathbf{4}$ dias após a emergência. Faculdade de Agronomia/UFRS, Porto Alegre, RS, 1990.

disponíveis para absorção via hipocótilo pelas plântulas de girassol (Figuras 1 a 3).

Os resultados obtidos nestes experimentos permitiram concluir que:

» clomazone é potencialmente injurioso para o girassol;

» clomazone promoveu injúria inicial mais acentuada em pré-emergência do que em pré-plantio incorporado;

» a fitotoxicidade de clomazone em pre-plantio incorporado se acentuou com o decorrer do tempo, a ponto de desaparecerem as diferenças entre épocas de aplicação;

》 o posicionamento de clomazone no solo determina a via de absorção e o grau de dano ao girassol.

\section{AGRADECIMENTOS}

Ao Dr. João Riboldi, do Instituto de Matemática da UFRS, pelo apoio na análise estatística dos resultados.

\section{LITERATURA CITADA}

ANDERSON, W. P. Weed science; principles. Saint Paul, West, $1977.598 \mathrm{p}$.

ASHTON, F. M. \& DUNSTER, K. The herbicidal effect of EPTC, CDEC, and CDAA on Echinochloa crusgalli with various depths of soil incorporation. Weeds, Champaign, 9: 312-317, 1961.

BLACKMAN, P. G. \& DEVESON, M. R. The origins of selectivity and performance of a new pre-emergence bleaching herbicide. Part II: Plant and environmental factors influencing biological activity. Pesticide Science, London, 28: 143-156, 1990.

BURNSIDE, O. C. Tolerance of soybean cultivars to weed competition and herbicides. Weeds, Champaign, 20: 294-297,1972.

CHEW, V. Comparing treatment means: a compendium. HortScience, Alexandria, 11: 348-357, 1976.

CURRAN, W. S. \& KNAKE, E. L. Rotational crop injury potential for corn following clomazone, imazaquin, imazethapyr and chlorimuron in Illinois In: MAINZ, M. J. \& SUTOR, J. J. Northwestern Illinois Agricultural Research and Demonstration Center, Report of Research Results. Urbana-Champaign, Univ. of Illinois, 1987. p. 114-119.

DAVIS, D. E. Some factors that affect the phytotoxicity of water-soluble DNBP. Weeds, Champaign, 4: 227-234, 1956. 
DOWLER, C.; BAUGHMAN, N. M. \& VEATCH, C. The effect of soil type, soil $\mathrm{pH}$, and simulated rainfall on the distribution of DNBP in the soil. Weeds, Champaign, 6: 281-288, 1958.

FRANS, R.; TALBERT, R.; MARX, D. \& C Y, H. Experimental design and techniques for measuring and analysing plant responses to weed control practices. In: CAMPER, N. D. ed. Research methods in weed science. 3.ed. Champaign, SWSS, 1986. p.29-46.

GALLANDT, E. R.; FAY, P. K. \& INSKEEP, W. P. Clomazone dissipation in two Montana soils. Weed Technology, Champaign, 3: 146-150, 1989.

GOMEZ, K. A. \& GOMEZ, A. O. Statistical procedures for agricultu ral resear ch. 2.ed. New York, Wiley, 1984.680p.

HALSTEAD, S. J. \& HARVEY, R. G. Effect of rate and carrier on clomazone movement off-site. Weed Technology, Champaign, 2: 179-182, 1988.

HAMID, Z. A. \& GRAFIUS, J. E. Developmental alometry and its implication to grain yield in barley. Crop Science, Madison, 18: 83-86, 1978.

KEIFER, D. W. Tolerance of corn lines to clomazone. WeedScience, Champaign, 37: 622-628, 1989.

KNAKE, E. L; APPLEBY, A. P. \& FURTICK, W. R. Soil incorporationand site of uptake of preemergence herbicides. Weeds, Champaign, 15: 228-232, 1967.

KNAKE, E. L. \& WAX, L. M. The importance of the shoot of giant foxtail for uptake of preemergence herbicides. Weed Science, Champaign, 16: 393-395, 1968.

LOUX, M. M.; LIEBL, R. A. \& SLIFE, F. W. Adsorption of clomazone on soils, sediments, and clays. Weed Science, Champaign, 37: 440-444, 1989.

LOUX, M. M. \& SLIFE, F. W. Availability and persistence of imazaquin, imazethapyr e clomazone in the soil. Weed Science, Champaign, 37: 259-267, 1989.

NOGUEIRA, I. R. Método geral para obtenção de tabelas de polinômios ortogonais. Revista de Agricultura, Piracicaba, 53: 269-279, 1979.
PAT ERSON, D. T. The effects of shading on the growth and photosynthetic capacity of itchgrass (Rottboellia exaltata). Weed Science, Champaign, 27: 549-553, 1979.

PATTERSON, D. T. Effects of shading and temperature on showy crotalaria (Crotalaria spectabilis). Weed Science, Champaign, 30: 692-696, 1982.

PETERSEN, R. G. Use and misuse of multiple comparison procedures. Agronomy Journal, Madison, 69: $205208,1977$.

RADOSEVICH, S. R. \& HOLT, J. S. Weed ecology; implications for vegetation management. New York, Wiley, 1984. 265p.

ROBINSON, R. G. Sunflower-soybean and grain sorghumcorn rotations versus monoculture. Agron omy Journal, Madison, 58: 475-477, 1966.

ROBINSON, R. G. Control by tillage and persistence of volunteer sunflower and annual weeds. Agronomy Journal, Madison, 70: 1053-1056, 1978.

SILVA, P. R. F. da Sucessão e rotação de culturas. In: UFRS/SEC. AGRIC. Girassol; Indicações para o cultivo no Rio Grande do Sul. P. Alegre, UFRS/Sec. Agric., 1988. p.63-66.

SILVA, P. R. F. da \& MUNDSTOCK, C. M. Época de semeadura. In: Girassol; Indic ações para o cultivo no Rio Grande do Sul. P. Alegre, UFRS/Sec. Agric., 1988. p.13-17.

VRANCEANU, A. V. Tecnica del cultivo. In: El Girasol. Madrid, Ed. Mundi-Pren sa, 1977 . p.247 313.

WILKINS, H. D. \& SW ALLERS, C. Sunflower production in North Dakota. Fargo, N. Dakota State Univ.- Coop. Ext. Serv., 9p. 1982. (Circular, A-538 rev.)

WITT, W. W. Persistence of imazaquin, imazethapyr, and clomazone in notill double-crop soybeans. In: PASCALE, J. A. ed. Conferencia Mundial de Investigacion en Soya, 4, Buenos Aires. Actas ... Buenos Aires, J. A. Pascale, 1989. p.1683-1688.

WSSA Herbicide handbook. 6.ed. Champaign, WSSA, 1989.301p. 